\section{Fresidential Address}

orr

\section{RECENT ADVANCES IN THE STUDY OF CARDIO-VASCULAR DISEASE.}

\author{
Deltvered before the Ulster Branch of the British \\ Medioal Assoctation, November, 1924,
}

BY

J. E. MacILWAINE, M.D., B.Sc., D.P.H.,

VISITING PHYSICIAN, ROYAL VICTORIA HOSPITAL, BELFAST; PROFESSOR OF MATERIA MEDICA AND THERAPEUTICS, QUEEN'S UNIVERSITY, BELFAST.

Tre word "study" in the title of this address. has been used with the idea that the address may cover a considerable amount of matter which has not as ret, perhaps, reached its full practical utility. I shall endeavour, on the other hand, to discuss the questions taken up in as practical a manner as possible. The period taken as being covered by the term "recent" is merely defined by the period since my own graduation in medicine-twenty-three years. I had intended to give some points with regard to the history of the study of cardio-vascular disease, but time will not permit more than a mention of a very few names.

I think it may be said that four hundred years ago Harvey laid the basis of all real study of cardio-vascular disease. Before his time the views held on the mechanism of the circulation were so speculative and so dissociated from reality that it is difficult to-day to conceive how such ideas could exist.

About a hundred years ago auscultation had led to a definite recognition of the origin and cause of the first and second sounds of the heart, and the question of murmurs was being thoroughly investigated. Just seventy years ago E. J. Marey ${ }^{1}$ began the development of his instrumental methods, based upon air transmission of pulsation, and opened up entirely new ground with regard to the study of cardio-vascular disease.

Broadbent's book on the discases of the heart, published in 1897, might be considered representative of the position of clinical cardiology just before the period termed "recent." I left the Royal Victoria Hospital at the beginning of this period, having had, under Professor Lindsay, as good an opportunity of learning cardiac work as anr young graduate could desire.

It is proposed to consider the recent adrances under four heads:

I. Advances in the study of the mechanism of the circulation.

II. Advances in knowledge of the functional activity of some of the organs of the body, obtained by recent biochemical methods.

IIT. Altered views, from a bacteriological and pathological standpoint.

IV. Recent pharmacological development.

\section{The Circulatory Mechanism.}

In considering the circulatory mechanism the first point we must take up is our altered view of the mechanism of the heart-beat. This alteration of view means that to-day we recognize the sinus node at the venous-auricular junction as the "pace-maker" of the heart. This node throws in its impulses with the regullarity which constitutes the " dominant rhythm of the heart." These impulses start the wares of contraction which flow over the auricle to arrive at the $A-\nabla$ junction. Here they encounter the auriculo-ventricular node, and, through this node, transmit their stimulus down the right and left branches of the auriculo-ventricular bundle. Each A-V branch goes to its respective rentricle, terminating in the Purkinje's fibres, thus constituting a conducting system, which apparently stimulates the true cardiac muscle to contract.

In 1901, when studying at the Nothnagel clinic in Vienna, I took a course upon cardiac disease, and in no part of the course was there any discussion whatever of the analysis of a single heart-beat, although in the textbook recommenderl (Sahli's Untersuchungs Methoden) as an appendix there was a discussion, with pulse tracings, of the irregular pulse. The analysis of Wenckebach and Engelmann separated the irregular pulse, due to the extra-systole, from the completely irregular pulse, which we now know to be due to auricular fibrillation.

Then came the epoch of Mackenzie's work, which dominated all clinical cardiologr. It was based upon the analysis of the single heart-beat, using for this purpose the jugular pulse or venous tracing, correlated with the arterial pulse, etc. ${ }^{2}$ If we examine the venous tracing we find that there is a wave which synchronizes with the time of contraction of the auricle, and Mackenzie noted that this wave had disappeared when complete irregularity of the pulse existed. He established definitely that the auricle was not working normally under these conditions. It was left, however, for Lewis to demonstrate that the auricle was fibrillating; but Mackenzie's work placed cardiology upon a new basis, and definitely gave us a true classification of the cardiac irregularities. Auricular flutter had been previously recognized by Ritchie and Jolly, by aid of the electrocardiograph. Clinical electro-cardiography, which will always be associated with the name of Thomas Iewis, ${ }^{3}$ has introduced into medicine an entirely new method of examination -namely, a graphic record of an electrie: pulsation in the body, which is synchronous with the passage of the wave of contraction over the heart muscle. These graphic records gave us the foundation of our classification of cardiac arrhythmias-namely, sinus arrhythmia, the auricular extra-systole, the rentricular extra-systole, auricular fibrillation, and auricular flutter, together with complete and partial heart-block. The newer method of electro-cardiography gives a further indication which has been interpreted as the occurrence of a block in the conducting system of the heart beyond the auriculo-ventricular junction -namely, in one of the branches of the $\mathrm{A}-\mathrm{V}$ bundle; that is, either to the right or left rentricle. The electro-cardiogram presents another physical sign, inasmuch as the wave which synchronizes with the ventricular contraction in the heart, the $T$ wave, may become altered, or inverted. This inversion or negativity of the $\mathrm{T}$ wave, which occurs in certain electro-cardiographic tracings, has been shown statistically to be a phrsical sign of grave inport in cardiac prognosis (Willius ${ }^{4}$ ). 'Thus from the study of the mechanism of the heart-beat knowledge has been obtained which has given a definite classification of the cardiac irregularities, and also definite indication of lesions of the heart which involve the conducting tissue in that organ.

Taking up next the consideration of the mechanism of the circulation in the arteries, blood pressure has become such a well known phenomenon, even amongst the lay public, that it is necessary to say something regarding its estimation. About 1887 it became a clinical method, and RivaRocci in 1897 designed the instrument which is probably most used to-day in clinical work. In 1905 Korotkow introduced a method for estimating the diastolic pressure. The estimation of the systolic pressure is easily carried out. Our ability to estimate correctly the diastolic pressure is not unchallenged. In most cases, when using the auscultatory method, there is a distinct sudden change in the character of the "knock" heard over the brachial artery, and I think the record of this point of change as the diastolic pressure is most valuable. Macleod, in his Physiology, ${ }^{5}$ states that the diastolic pressure is the dead load of the circulation, and is the pressure which the aortic cusps, great vessels, and arteries have got continually to bear. I consider a diastolic pressure which is permanently raised is of much prognostic importance, and it is sometimes relatively unaltered when there is a marked fall of the systolic pressure.

It has been recognized that a single estimation of blood pressure may give a wrong idea of the condition present in some patients. It may be necessary to chart daily the record of blood pressure in order to note how variable it is. A variation of $60 \mathrm{~mm}$. of mercury in the systolic pressure mav be seen in forty-eight hours. The difference in millimetres of mercury between the systolic pressure and the estimater diastolic pressure is called the "pulse pressure." This observation is used clinically, but we do not as yet know quite how to assess its true value. I have always thought that the great difficulty in regard to pulse pressure is the 
farct that wo are unable to obtain a true curve of pulse pressure. We have but two points on this record-namely, the systolic and diastolic pressures-but we have no intervoning curve upon a true time base. It would only be by ohtaining such a curve that we could integrate this true pulse pressure into work.

Very recently the anatomy and physiology of the capillaries hare been studied by $\mathrm{Krogh}^{6}{ }^{6}$ and his work, in conmexion with that of Dale and other's, makes it perfectly clear that a capillary paresis, or a filling up of the capillaries of the body with blood, may be the source of a circulatory failure. Thus we have the picture of traumatic and histamine shock, where the arterial system is insufficiently filled because the heart lacks a proper supply of blood from the veins. In othei words, the heart is beating rapidly, but receiving relatively little blood, because of the lagging of blood in the capillary system of the body. We must bear this in mind when considering the question of toxic death. It is not sufficient simply to say "cardiac failure" and think that means a failure of the cardiac muscle, any more than that this muscle is, like the rest of the tissue of the body, insufficiently supplied with blood, owing to a lack of blool volume in the arterial system. The treatment of such cases in surgery has to-day become a matter of filling up the circulation by the transfusion of blood or gum saline, etc.

Under the head of the circulatory mechanism we must consider the altered views which a knowledge of the involuntary norvous srstem, such as presented by Gaskell, ${ }^{7}$ brings with it. From the diagram it is seen that the vagus and

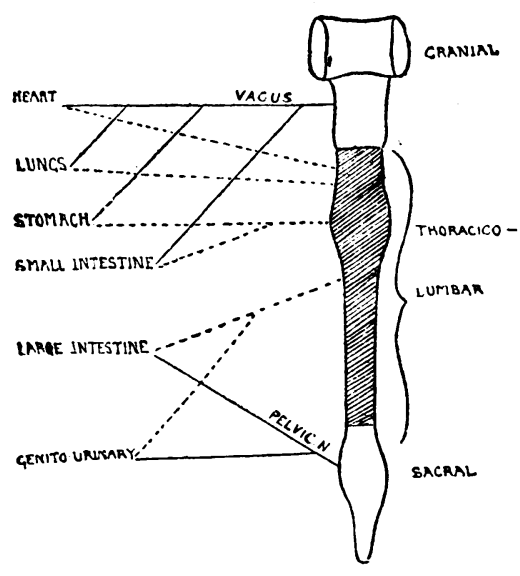

Autonomic Nerrous Sustem. pelvic nerves represent the cranial and the sacral outflow of involuntary nervous impulses ; they go, in the case of the vagus, to the heart, lungs, stomach, and small intestine, as far as the ileo-caecal valve; whereas the pelvic nerve, or sacral outflow, goes to the colon and the genito-urinary system. These nerves are opposed in their action by what we used to call the sympathetic system, and are often spoken of as parasympathetic nerves. The sympathetic system is that portion of the involuntary or autonomic nervous mechanism which comes from the thoracico-lumbar cord. This sympathetic sends fibres to the heart, lungs, stomach, small intestine, large intestine, genito-urinary system, etc., to antagonize the parasymathetic fibres. We have only recently begun to grasp the clinical meaning of this involuntary neuromuscular mechanism. When dealing with the problem of D.A.H. (disordered action of the heart) it seemed, at the oud of the work which had been carried out, that an explanation of this condition might lie in an instability of this involuntary neuro-muscular mechanism. So much was I impressed with this instability, which appeared to bo either inherent or toxic in origin, that I could not help thinking how often in common language the actions of this involuntary mechanism are expressed. Thus wo lemember the expressions "He has no heart"; "He has no stomach for the fight"; "He has no guts"; and it is well recognized how uncontrolled the sphincters may be as the result of emotion. Further, these involuntary reactions upon an emotional basis bring into consideration their association with the secretions of the endocrine glands. While theso ideas are ret speculative and theoretical, out of the knowledge of the autonomic control of the heart there has come a more definite understanding of the anginal syndrome; and here one must allude to Sir James Mackenzie's work upon the segmental association of the pain reflex and visceral sensations in the spinal cord. In the recently published monograph on Angina Pectoris ${ }^{8}$ we see this work in its true perspective and are able to appreciate the practical application of his principles in classifying this condition into a "primary" and a " secondary" form. It was upon this same subject-the interrelation of visceral and somatic sensation-that Dr. Ivy Mackenzie touched when speaking in this lall in the spring of this year. In his paper "The reactions of the ulnar nerve in disease" we have a good example of how modern advance in neurology can illuminate a clinical problem. Professor Daniélopolu's paper in a recent number of the Britrsy Medical Joursal ${ }^{10}$ discusses the surgical treatment of angina by section of afferent fibres from the heart in this involuntary nervous system. One interesting idea arising from the consideration of Professor Daniélopolu's diagran is the vasomotor reflex from the heart acting upon the lungs. It may, perhaps, aid us theoretically to explain some of tho cases of cardiac asthma in which, apparently, no real anoxaemia is present. I would utilize this conception of the relation of heart with stomach and intestine thiough the involuntary nervous system to impress upon you the immense importance of dietetic treatment in cardiac cases. How much more we will get out of our study of the involuntary system it is difficult to foresee, but I believe that clinically it will be more and more helpful in the solution of problems which to-day are unsolved.

\section{Biochemical Tests and Function.}

As a result of biochemical methods Hill, Haldane, Meakins, and other observers have been able to give us figures of a most illuminating character with regard to tho volume of blood which flows through the heart in a minute. Roughly, in a man at rest, a normal heart may pump about 7 litres of blood through in a minute. By active exercise this ean be increased up to 30 litres. The exact amount per heart-beat is thus easily calculated. When there is failure of compensation, Meakins ${ }^{11}$ has shown that, in spite of a large dilated heart, the minute-volume may be as low as $2 \frac{1}{2}$ litres; and ho further demonstrated, in some of Ritchie's ${ }^{12}$ patients, that as failure increased this minutevolumo diminished. These figures allow us to appreciate what cardiac decompensation really means, and let us visualize the importance of absence of ris a tergo when wo discuss "back pressure" as an increased resistance to the onflow of the blood. Did we know the exact volume of blood per heart-beat, and had an exact time record of aortic and pulmonic pressure, we could state in absolute mechanical terms the work of the heart. These figures are not yet clinically available.

Another advance in the study of cardio-vascular disease has been that biochemists have placed at our disposal methods of estimation of renal function which enable us to diagnose the presence of renal disease. To separate clearly a cardiac condition which is associated with renal inadequacy is a great help in diagnosis, and also, necessarily, in treatment. I would only mention that the choice of a diuretic, if a diuretic is to be used at all, must largely be governed by our knowledge of the state of the kidney function.

The third biochemical assistance in cardio-vascular diagnosis is that by estimation of the metabolic rate a figure is given which determines whether hypothyroidism is present, and somewhat gauges the extent. Recent work on the thyroid has tended to separate a group of thyroid patients where the condition is to be described as that of a toxic adenoma of the gland. It would appear that a toxic adenoma is practically a malignant condition. Gradually the intoxication increases, and relentlessly the cardiopathy progresses. A clear case would seem to be made in this condition for carly removal of the " malignant" tumour.

\section{Pathology and Bacteriology.}

Under this heading let us first consider the rheumatic heart. This has been well described from a pathological point of riew by Carey Coombs, ${ }^{13}$ who puts forward most clearly the observation that in this pancarditis, as he calls it, the myocardium is always markedly involved, and, just as joints and subcutaneous rheumatic nodules resolve, these submiliary myocardial nodules tend to disappear without much injury to the muscle, whereas in the poorly rascularized endocardial ralres resolution is impossible and cicatrization results. These pathological facts alone aro 
sufficient to emphasize the necessity of prolonged rest in children who have had rheumatic infection. In fact, the suggestion of sanatorium treatment and notification of acute rheumatic infection is well worthy of consideration.

Next the syphilitic heart. Here the pathology of the arterial change and the recognition of the involvement of the myocardium as well as the great blood vessels, in this progressive lesion, makes it a great additional advantage in prognosis and treatment of cardiac cases to obtain the evidence of a positive Wassermann reaction.

Horder and Libman ${ }^{14}$ separate a group of cases of subacute infective endocarditis ' $w$ ith very definite clinical signs such as described by Cotton ${ }^{15}$ and others. Under the title "endocarditis lenta," Starling ${ }^{16}$ and Carey Coombs ${ }^{17}$ have presented groups of cases of unusual interest; and if this condition, which anyone connected with cardiac work must have seen, is to be associated with an enterococcal type of infection we have an etiological asset of great importance. Unfortunately, so far the treatment of these chronic endocarditis cases has been practically hopeless.

\section{Pharmacology.}

My fourth and final point with regard to advance is the consideration of the pharmacological aspect of cardiac disease. I do not intend to do more than indicate briefly the changes which have taken place with regard to teaching concerning remedies in common use. This group of scientists, the pharmacologists, are pushing steadily ahead, and to-day the student is taught, from a pharmacological point of view, what is the site of action of the remedy he is going to use. In such a subject, so recent and rapid in its development, we are bound to find unconfirmed statements and controversial points; but I believe that, just as physiology has now laid the recognized basis of our clinical teaching in medicine, so will pharmacology be the recognized basis of teaching of therapeutics. Pharmacologists are extending their sphere of action into consideration of problems of immunity, and one hopes that in this field they will equally show their powers of advance. To take, as an example, digitalis, its mode of action and its contained glucosides are to-day more fully understood, and thus we teach that its greatest advantage in therapeutics is the slowing of the ventricle, mainly by the depressing of conduction from auricle to ventricle. $\mathrm{Or}$, again, one may consider the change of method of the administration of digitalis, as suggested by Eggleston, in large doses-a drachm and a half, followed by a drachm in six hours, and a drachm six hours later. The success claimed for this method will teach us not to rely upon small doses in urgent cases, but it is also well to remember that we must always standardize our doses of digitalis by observation of the patient.

One or two points on which we have pharmacological backing are: that calomel need not be avoided as a diuretic in renal disease associated with cardio-vascular change and oedema; that morphine, in medicinal doses, has practically no effect upon the cardiac muscle; it has a central or cerebral depressant action of enormous value; jt does not influence to any extent the kidney secretion, and, except where respiratory depression must be avoided, can be given with.safety in all cardiac cases.

Quinidine, a remedy of very recent introduction, is still under judgement. One point the pharmacologists have told us is that it is a depressant of the cardiac muscle, and experience has shown that we must carefully control its administration as it quickens the ventricle in the majority of cases. These two facts are most important where there is any question of the likelihood of failure of compensation. The use of adrenaline in Stokes-Adams disease, as suggested by Parkinson, and in the sudden cardiac emergency of chloroform poisoning, must also be noted. What exactly is the effect of pituitrin on capillary paresis has yet to be tested out.

There is no doubt that the work which is being undertaken from a pharmacological point of view will give us back, with a renewed confidence in them, many remedies which have been' neglected.

In concluding this attempt to review some of the recent advances in the study of cardio-vascular disease it might be said there are two distinct lines upon which progress has been made. The increase of knowledge of structure, mechanism, and function gives us a better basis for the recognition of the changes produced by disease-that is, an increased refinement of diagnostic classification. If, on the other hand, we assume that the incidence of the disease precedes these recognized changes, a point Sir James Mackenzie emphasizes, we will appreciate how developments in the study of etiology and immunity will bring with them a hope of new therapeutic methods.

\section{REFERENCES}

1 E. J. Marey : La Circulation du Sang, 1881. 2 Sir James Mackenzie : The Study of the Pulse, 1902; Diseases of the Heart, 1908. 3 Sir Thomas Lewis : The Mechanism of the Heart-beat, etc. ${ }^{4} \mathrm{~F}$. A. Willius: Electrocardiography and Prognosis, Arch. Int. Med., October, 1922. ${ }^{5} \mathrm{~J}_{\text {. J. R. Macleod : }}$ Physiology and Bioolemistry in Modern Medicine, 1921. 6 A. Krogh : The Anatomy and Physiology of the Capillaries, 1922. ${ }^{7} \mathrm{~W}$. H. Gaskell : The Involuntary Nervous System, 1916. ${ }^{8}$ Sir J. Mackenzie: Angina Pectoris, 1923. Ivy Mackenzie : Edin. Med. Journ., August, 1924. 10 BRITISH MED. T. Ritchie: The Response of the Heart in Health and Disease, Edin. Med. Journ., December, 1923. 13 Carey F. Coombs : Rheumatic Heart Disease, 1924. 14 BRITISH MEDICAL JoURAAL, 1920, il, pp. 301 and Jor. 1924 to : $307.16 \mathrm{H}$. W. Starling: Endocarditis Lenta, Quart. Journ. of Med, A, April, 1923. 17 Carey F. Coombs : Endocarditis Lenta, Quart. Journ. of Med., July, 1923

\section{Pectures}

ox

\section{THE SYMPATHETIC INNERVATION OF S'TRIA'TED MUSCLE.* \\ BY}

The Jate JOHN IRVINE HUNTER, M.D., Сh.M., CHALLIS PROFESSOR OF ANATOMY IN THE UNIVERSITY OF SYDNEY.

\section{LECTURE II.-PART I.}

\section{THE FUNCTIONS OF THE TWO GROUPS OF} MUSCLE FIBRES :

\section{EXPERIMENTAL EVIDENCE.}

Is the first lecture I submitted the evidence that has accumulated during the last half-century in demonstration of the fact that the striated muscles of vertebrates consist of two kinds of fibres (in addition to the muscle spindles) and that the difference in their innervation is as distinct as the contrast in their anatomical features, one group being controlled by the spinal cord through medullated somatic nerves, the other by the central nervous system through the intermediation of the sympathetic system, the postganglionic non-medullated grey rami communicantes.

In the present lecture I propose to discuss the evidence obtained by cutting the sympathetic and the somatic nerves respectively in proof of the fact that the functions of the two groups of muscle fibres are as sharply distinguished as their structure and mode of innervation. Our preliminary experiments were made upon goats, not only because they are large animals with the simplest type of "standing reflexes," but also because Royle and I had acquired some experience of these animals under experimental conditions in the course of our investigations on spinal shock in 1920 and 1921.

The details of the experiments upon the goat have been given in the earlier accounts of our work in the Medical Journal of Australia. I can more usefully employ the time at my disposal in these lectures to explain the principles that guided us in our work and to discuss the results and certain technical points that throw light upon the issues in the present controversies.

In Fig. 3 the essential connexions of the sympathetic system are represented in a purely diagrammatic way. The white rami communicantes that issue from the spinal cord in the thoracic and upper lumbar region end in the ganglia of the sympathetic cord (or in one of the peripheral ganglia not shown in the diagram). From the sympathetic ganglion two series of non-medullated nerves emerge-one proceeding directly to the viscera of the thorax and abdomen, the other, forming the grey rami communicantes, passing to the

* Delivered by Professor Elliot Smith at University College, January $26 \mathrm{th}, 1925$. 